Article

\title{
Sodium Alginate-Based Green Packaging Films Functionalized by Guava Leaf Extracts and Their Bioactivities
}

\author{
You Luo ${ }^{1}$, Haiqing Liu ${ }^{1,2}$, Shanzhong Yang ${ }^{1}$, Jiarui Zeng ${ }^{1}$ and Zhenqiang $\mathrm{Wu}^{1, *}$ \\ 1 School of Biology and Biological Engineering, South China University of Technology, \\ Guangzhou 510006, China \\ 2 Department of Biological Engineering, Pan Asia (Jiangmen) Institute of Biological Engineering and Health, \\ Jiangmen 529080, China \\ * Correspondence: btzhqwu@scut.edu.cn
}

Received: 8 August 2019; Accepted: 9 September 2019; Published: 10 September 2019

\begin{abstract}
The aim of this work was to develop green and bioactive films with sodium alginate incorporating guava leaf extracts. Seven formulations were performed with a different sodium alginate: Guava leaf water extract (WE)/ethanolic extract (EE) proportions (100:0, 90:10, 85:15, 80:20), and glycerol were used as a plasticizer. The HPLC-PDA analysis showed the main phenolic

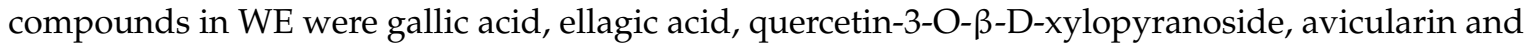
quercetin. The main polyphenols in EE were rutin, isoquercitrin, quercetin-3-O- $\beta$-D-xylopyranoside, avicularin, quercitrin, quercetin and kaempferol. Guava leaf extracts could greatly enhance the antioxidant activity, antibacterial activity, tensile strength and water solubility of the sodium alginate film as well as the water barrier property, while inducing a decrease in the moisture content and elongation at the break. The FTIR and SEM analyses indicated that intermolecular hydrogen bonding between the guava leaf extract and sodium alginate resulted in a more compact structure in the composite films. These results indicated that sodium alginate-guava leaf extract films might be developed into antiradical and antimicrobial food packaging materials.
\end{abstract}

Keywords: bioactive film; sodium alginate; guava leaf extract; polyphenol; antioxidant; antibacterial

\section{Introduction}

Worldwide, 8.3 billion tons of plastics have been produced, of which 6.3 billion tons have become plastic waste, causing serious environmental pollution [1]. Now the whole world is declaring war on plastic and seeking alternatives to plastics. Biodegradable and edible food packaging materials have become a research hotspot due to the serious white pollution and health concerns [2,3]. Biopolymers, such as polysaccharides, protein and lipid have been developed into food packaging materials [4-6]. Among the varieties of biopolymers, sodium alginate, a natural polysaccharide, is a good candidate for a biopolymer film or coating due to the excellent colloidal properties such as its film-forming property, stability, gelation and biocompatibility $[7,8]$. Furthermore, the active packaging film is designed to extend the shelf life of a product and maintain nutrition, freshness and safety [9]. The main factors of food spoilage are oxidation and microorganisms. Hence, active packaging should include antioxidants and bacteriostats to prevent unfavorable factors.

Plant polyphenols and extracts are natural antioxidants and bacteriostats. The antioxidant mechanism of polyphenols mainly depends on their abilities for scavenging reactive oxygen species and chelate metal ions [10]. The bacteriostatic effects of plant-derived polyphenols depend upon the hydroxyphenyl structure [11]. Therefore, polyphenols or plant extracts, such as tea polyphenols [12], green apple skin extracts [9] and thyme extract [13], can greatly promote the antioxidant, antibacterial 
and physical properties of film. From the point of view of resource recycling and environmental protection, it seems more profitable to utilize agricultural by-products, such as peel extracts and plant leaf extracts, as active components of the films. Guava (Psidium guajava Linn.) is a common fruit plant available in many regions in tropical and subtropical climates. Guava leaf has been used as a herbal tea in China, Japan, India, et al. for many years because of its extensive bioactivities and pharmacological effects $[14,15]$. Previous studies have verified that the extracts from guava leaves exhibited antioxidant and antibacterial activities [16-18].

Yang et al. (2018) improved the chemical and mechanical properties of alginate-based films by adding polyvinyl alcohol and $\mathrm{SiO}_{2}$ [19]. Costa et al. (2018) verified that the tensile strength of sodium alginate-based films crosslinked with $\mathrm{CaCl}_{2}$ increased, and the moisture content and water solubility decreased [20]. Salama et al. revealed that chitosan biguanidine incorporated in sodium alginate markedly elevated the antibacterial ability of the films [21]. However, there are a few reports about the physical properties and bioactivities of sodium alginate/phenolic-rich plant extracts composite films. The purpose of this work is to prepare antioxidant and antibacterial sodium alginate-based films by adding different amounts of guava leaf water extract (WE)/ethanolic extract (EE). Firstly, the sodium alginate/guava leaf extracts composite films were prepared. Then, the physical properties, antioxidant and antibacterial activities of those composite films were assessed and compared with plain sodium alginate film.

\section{Materials and Methods}

\subsection{Materials}

Firstly, 1,1-Diphenyl-2-picrylhydrazyl (DPPH) and sodium alginate (product number: S817374; AR, purity $\geq 90 \%$; viscosity $\left.\left(1 \%, 20^{\circ} \mathrm{C}\right), 260 \mathrm{mPa} \cdot \mathrm{s}\right)$ were purchased from Macklin Biochemical Co., Ltd. (Shanghai, China). Glycerol and Absolute ethanol (AR) were obtained from Tianjin Zhiyuan Chemical Reagent Co., Ltd. (Tianjin, China). Gallic acid, chlorogenic acid, $p$-hydroxybenzoic acid, caffeic acid, rutin, isoquercitrin, quercetin-3-O- $\alpha$-L-arabinoside, ellagic acid, avicularin, quercetin, quercitrin, kaempferol were purchased from Aladdin Industrial Corporation (Shanghai, China).

Staphylococcus aureus (ATCC29215) and Escherichia coli (ATCC25922) were provided by the Microbiology Laboratory of South China University of Technology (Guangzhou, China).

Guava leaves were collected in October, 2018 and supplied by Jiangmen Nanyue Guava farmer cooperatives (Jiangmen, Guangdong, China). The guava leaves were naturally dried and stored in the dark $\left(25 \pm 2{ }^{\circ} \mathrm{C}\right)$. Dried guava leaves were grounded into powders and passed through an 80 mesh sieve size.

\subsection{Obtaining Guava Leaf Extracts}

The guava leaf powder $(10 \mathrm{~g})$ was immersed in $100 \mathrm{~mL}$ of ethanol/water $(70 \%, \mathrm{v} / \mathrm{v})$ and distilled water, respectively. The extraction was conducted with an AS20500ATH ultrasonic cleaner bath (400 W, $40 \mathrm{KHz}$, Tianjin Automatic Science Instrument Co., Ltd., Tianjin, China) at room temperature for $30 \mathrm{~min}$. The mixture was centrifuged for $10 \mathrm{~min}$ and then the supernatant was obtained. The ethanolic extract (EE) and water extract (WE) as functional ingredients were added to the films.

\subsection{Films Preparation}

The films were prepared by casting with sodium alginate (SA), guava leaf extracts and glycerol (as plasticizer). The SA was dissolved in distilled water $(1: 100 \mathrm{~g} / \mathrm{mL})$ at $90^{\circ} \mathrm{C}$ under constant stirring for $1 \mathrm{~h}$ using a B11-2 constant temperature magnetic stirrer (450 r/min, Shanghai Sile Instrument Co., Ltd., Shanghai, China). Glycerol (Gly, $0.5 \mathrm{~g}$ ) was added into the SA solution. The different film formulations were illustrated in Table 1. The obtained films were entitled SAF (sodium alginate film), $10 \%$ WEF (sodium alginate incorporating 10\% water extract film), 15\% WEF (sodium alginate incorporating $15 \%$ water extract film), $20 \%$ WEF (sodium alginate incorporating $20 \%$ water extract film), $10 \%$ EEF 
(sodium alginate incorporating 10\% ethanol extract film), 15\% EEF (sodium alginate incorporating 15\% ethanol extract film), 20\% EEF (sodium alginate incorporating 20\% ethanol extract film), respectively.

Table 1. The formulations of the films.

\begin{tabular}{cccc}
\hline Sample & $\mathbf{1} \% \mathbf{S A}+\mathbf{0 . 5} \%$ Gly $(\mathbf{m L})$ & WE $(\mathbf{m L})$ & EE $(\mathbf{m L})$ \\
\hline SAF & 100 & 0 & 0 \\
$10 \% W E F$ & 90 & 10 & 0 \\
$15 \% W E F$ & 85 & 15 & 0 \\
$20 \% W E F$ & 80 & 20 & 0 \\
$10 \% E E F$ & 90 & 0 & 10 \\
$15 \%$ EEF & 85 & 0 & 15 \\
$20 \% W E F$ & 80 & 0 & 20 \\
\hline
\end{tabular}

The film-forming solutions $(50 \mathrm{~mL})$ were poured into $10 \times 10 \mathrm{~cm}$ square Petri dishes and dried in a $50{ }^{\circ} \mathrm{C}$ oven. The formed films were kept at $20^{\circ} \mathrm{C}$ and $50 \%$ relative humidity (RH) in a constant temperature and humidity incubator for 3 days before further tests.

\subsection{Characterization}

\subsubsection{Chemical Composition of Extract}

The total polyphenol content of the extract was measured by the Folin-Ciocalteu method [22]. The reaction system consisted of the Folin-Ciocalteu reagent, $20 \% \mathrm{Na}_{2} \mathrm{CO}_{3}$ and the sample. The absorbance was read at $765 \mathrm{~nm}$ by a Multimode Plate Reader (PerkinElmer, Singapore). The standard curve of polyphenol was plotted with gallic acid as the standard. The total phenolics content was expressed in milligrams gallic acid equivalent (GAE) per milliliter of the extract.

The extract of guava leaf and phenolic standards (gallic acid, chlorogenic acid, $p$-hydroxybenzoic acid, caffeic acid, rutin, isoquercitrin, quercetin-3-O- $\alpha$-L-arabinoside, ellagic acid, avicularin, quercetin, quercitrin, kaempferol) were performed on SunFire C18 column $(250 \times 4.6 \mathrm{~mm}, 5 \mu \mathrm{m}$, Waters, USA) and detected by high performance liquid chromatography (HPLC) with photo-diode array (PDA) (Waters, USA). The mobile phase $\mathrm{A}$ and phase $\mathrm{B}$ were $0.1 \%$ formic acid solution and acetonitrile, respectively. The elution condition: 0-5 min, 15\% B; 5-10 min, 15-20\% B; 10-20 min, 20-25\% B; 20-30 min, 25-35\% B; 30-40 $\mathrm{min}, 35-50 \% \mathrm{~B} ; 40-50 \mathrm{~min}, 80 \% \mathrm{~B} ; 50-55 \mathrm{~min}, 15 \% \mathrm{~B}$. The flow rate was $0.8 \mathrm{~mL} / \mathrm{min}$, the injection volume was $10 \mu \mathrm{L}$, the column temperature was $30^{\circ} \mathrm{C}$, and the detection wavelength was $200-600 \mathrm{~nm}$.

\subsubsection{Fourier Transform Infrared (FT-IR) Analysis}

The film was mixed with $\mathrm{KBr}$ and submitted to the FT-IR analysis. The FT-IR spectra were determined by a Nexus Por Euro Fourier transformation infrared spectrometer (Nicolet, Madison, WI, USA) in the range of $4000-400 \mathrm{~cm}^{-1}$.

\subsubsection{Scanning Electron Microscopy (SEM)}

The film samples were cryo fractured in liquid nitrogen and sprayed with gold. The microstructure of the film sample was observed by SEM (Zeiss, Oberkochen, Germany) at a voltage of $5 \mathrm{kV}$.

\subsubsection{Moisture Content and Water Solubility}

The moisture content $(\mathrm{MC})$ was determined by the weight loss of the film after drying to a constant weight at $105^{\circ} \mathrm{C}$. The moisture content was presented as $\mathrm{g}$ of water per $100 \mathrm{~g}$ of the sample.

The sample film $(1.5 \mathrm{~cm} \times 1.5 \mathrm{~cm})$ was weighed accurately $\left(\mathrm{W}_{0}\right)$ and soaked in $10 \mathrm{~mL}$ of deionized water. All samples were stirred continuously for $1 \mathrm{~h}$ at room temperature $\left(25 \pm 1^{\circ} \mathrm{C}\right)$. After centrifugation, the residue was dried to a constant weight $\left(\mathrm{W}_{1}\right)$ at $105^{\circ} \mathrm{C}$ [23]. 


$$
\mathrm{S} \%=\frac{(\mathrm{W} 0-\mathrm{W} 1)}{\mathrm{W} 0} \times 100 \%
$$

\subsubsection{Film Thickness}

The thickness of the films was measured with a digital micrometer (Sanliang Measuring Tools Co., Ltd. Dongguan, China) with an accuracy of $0.001 \mathrm{~mm}$. The average thickness was calculated by 6 random points on the film.

\subsubsection{Color Measurement}

The color parameters including L (lightness), a (red/green) and b (yellow/blue) of the films were measured with a Chroma meter CR-400 (KONICA MINOLTA OPTICS, INC. Tokyo, Japan). The colorimeter was calibrated using a standard white plate $\left(L^{*}=95.19, \mathrm{a}^{*}=-0.57, \mathrm{~b}^{*}=3.53\right)$. The color parameters were determined by three random points on each film.

\subsubsection{Water Vapor Permeability (WVP)}

The WVP value of the film was measured according to the ASTM (American Society for Testing and Materials) method [24]. Each film covered a permeation cell with an opening of $1.5386 \mathrm{~cm}^{2}$ at $20^{\circ} \mathrm{C}$ in a dryer. In order to maintain a $75 \% \mathrm{RH}$ gradient across the film, anhydrous $\mathrm{CaCl}_{2}$ was placed in the cell, and saturated $\mathrm{NaCl}$ solution was placed in the dryer. The water vapor transport depended on the weight gain of the cell. After reaching the steady state condition, the cells were weighed every $2.5 \mathrm{~h}$ for $25 \mathrm{~h}$. The change of cell weight was accurately recorded to $0.0001 \mathrm{~g}$ and plotted as a time function. The slope of each line was calculated by linear regression $\left(\mathrm{r}^{2}>0.99\right)$, and the water vapor transmission rate $\left(\right.$ WVTR) was calculated as the slope $(\mathrm{g} / \mathrm{s})$ divided by the film area $\left(\mathrm{cm}^{2}\right)$. WVP $\left(\mathrm{g} \cdot \mathrm{Pa}^{-1} \cdot \mathrm{s}^{-1} \cdot \mathrm{cm}^{-1}\right)=$ [WVTR/S $\left.\left(R_{1}-R_{2}\right)\right] d$, where $S$ is the saturation vapor pressure of water $(\mathrm{Pa})$ at the test temperature $\left(20^{\circ} \mathrm{C}\right), \mathrm{R}_{1}$ is the RH in the dryer, $\mathrm{R}_{2}$ is the $\mathrm{RH}$ in the permeation cell, and $\mathrm{d}$ is the film thickness $(\mathrm{cm})$. The driving force $\left[S\left(R_{1}-R_{2}\right)\right]$ was 1753.55 Pa. Each sample was repeated three times.

\subsubsection{Mechanical Properties}

The stress and strain analysis of the films was carried out by a DMA Q800 (TA Instruments, Newcastle, DE, USA) with a tension clamp. Three sample strips $(8 \times 30 \mathrm{~mm})$ of each formulation were tested using a ramp force constant rate of $0.4 \mathrm{~N} / \mathrm{min}$ to a static force of $18 \mathrm{~N}$, and the samples were ruptured. The force $(\mathrm{N})$ and deformation $(\mathrm{mm})$ were recorded during extension. The tensile strength $(\mathrm{MPa})$ and elongation at break (\%) were obtained from the stress-strain curves.

\subsubsection{Antiradical Activity}

The antiradical ability of the films was assessed by DPPH assay following Shimada's method with slight modification [25]. On the one hand, the different weights of the films (10, 15, 20, 25 and $30 \mathrm{mg}$, respectively) were put into $3 \mathrm{~mL}$ of $0.1 \mathrm{mM}$ DPPH solution. The reaction was carried out at room temperature in darkness for $60 \mathrm{~min}$. The absorbance of the reaction solution at $517 \mathrm{~nm}$ was measured by a microplate reader (PerkinElmer, Singapore). For the time-dependent antioxidant assay, $30 \mathrm{mg}$ of each film was put into $3 \mathrm{~mL}$ of $0.1 \mathrm{mM}$ DPPH solution. The absorbance was read at 10, 20, 30, 40, 50 and $60 \mathrm{~min}$, respectively. The scavenging DPPH radical ability was calculated as follows:

$$
\mathrm{DPPH} \text { radical scavenging rate }(\%)=\frac{\mathrm{Ab}-\mathrm{As}}{\mathrm{Ab}} \times 100
$$

where $\mathrm{Ab}$ is the absorbance at $517 \mathrm{~nm}$ of the methanol solution of $\mathrm{DPPH}$, as is the absorbance value at $517 \mathrm{~nm}$ of the sample. 


\subsubsection{Antimicrobial Properties}

The antimicrobial experiment was conducted according to the method reported by Otoni et al. with changes [26]. Escherichia coli and Staphylococcus aureus were cultured in Luria-Bertani (LB) culture for $8 \mathrm{~h}$. The number of microorganisims was calculated by a hemocytometer. Further, $200 \mu \mathrm{L}$ of inoculant containing $10^{6} \mathrm{CFU} / \mathrm{mL}$ of the microorganism was uniformly coated on a nutrient agar medium. Then, the $8 \mathrm{~mm}$ diameter films were placed on the respective culture medium and kept at $37^{\circ} \mathrm{C}$ for one day. The diameter (millimeter) of the inhibition zones was measured with a caliper. Each sample was repeated three times.

\subsection{Statistical Analysis}

The difference between the factors and levels was analyzed by ANOVA using SPSS 17.0. The Duncan test was used to compare the differences among the groups $(p<0.05)$. All data were list as the mean \pm standard deviation. The different comparisons among the groups were marked with different letters [12]. The average of each group was arranged from large to small. The group with the maximum average was marked with the letter " $a$ ", and then compared with the other averages. If the difference is not significant, the group is marked the same letter. If the difference is significant, the group is marked with another letter.

\section{Results and Discussion}

\subsection{Composition Difference between Water Extract and Ethanolic Extract of Guava Leaf}

The polyphenol content of each $1 \mathrm{~mL}$ water extract and ethanolic extract was $1.84 \mathrm{mg}$ and $2.94 \mathrm{mg}$ gallic acid equivalent, respectively. Polyphenols in guava leaf extracts were further analyzed by HPLC combined with PDA. The peaks were identified by the retention time, UV-Vis and mass spectra together with our previous work [17]. As shown in Figure 1, several principal components were detected at the wavelength of $350 \mathrm{~nm}$. The phenolic compounds in the guava leaf water extract were gallic acid $(0.0029 \mu \mathrm{g} / \mathrm{mL})$, ellagic acid $(0.0373 \mu \mathrm{g} / \mathrm{mL})$, quercetin-3-O- $\beta$-D-xylopyranoside $(0.0057 \mu \mathrm{g} / \mathrm{mL})$, avicularin $(0.0881 \mu \mathrm{g} / \mathrm{mL})$ and quercetin $(0.0001 \mu \mathrm{g} / \mathrm{mL})$. The main polyphenols in ethanolic extract were rutin $(0.0015 \mu \mathrm{g} / \mathrm{mL})$, isoquercitrin $(0.0291 \mu \mathrm{g} / \mathrm{mL})$, quercetin-3-O- $\beta$-D-xylopyranoside $(0.1290 \mu \mathrm{g} / \mathrm{mL})$, avicularin $(0.1225 \mu \mathrm{g} / \mathrm{mL})$, quercitrin $(0.0818 \mu \mathrm{g} / \mathrm{mL})$, quercetin $(0.0332 \mu \mathrm{g} / \mathrm{mL})$ and kaempferol $(0.0050 \mu \mathrm{g} / \mathrm{mL})$. The results indicated that the types of phenolic compounds in these two extracts were different and the content of polyphenols in EE was much higher than WE.

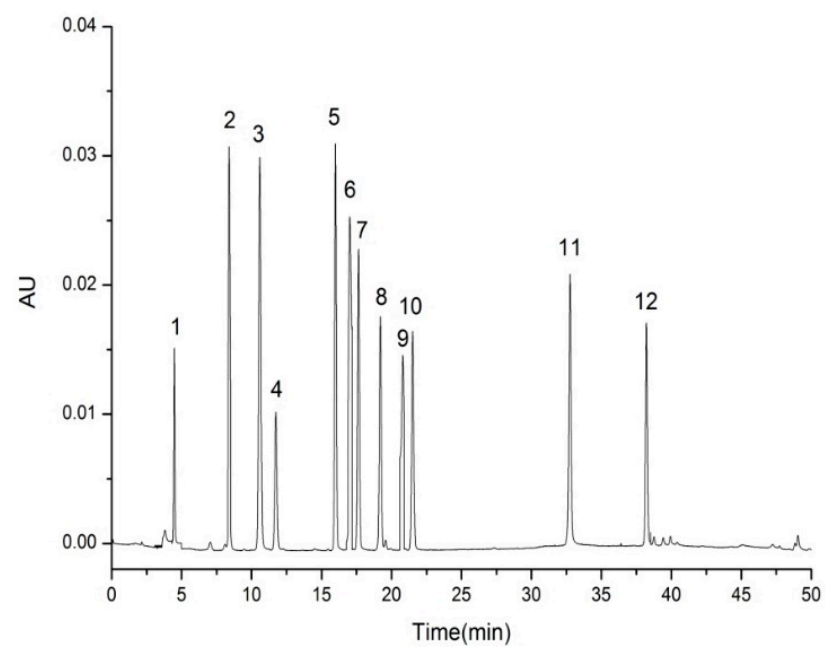

(a)

Figure 1. Cont. 


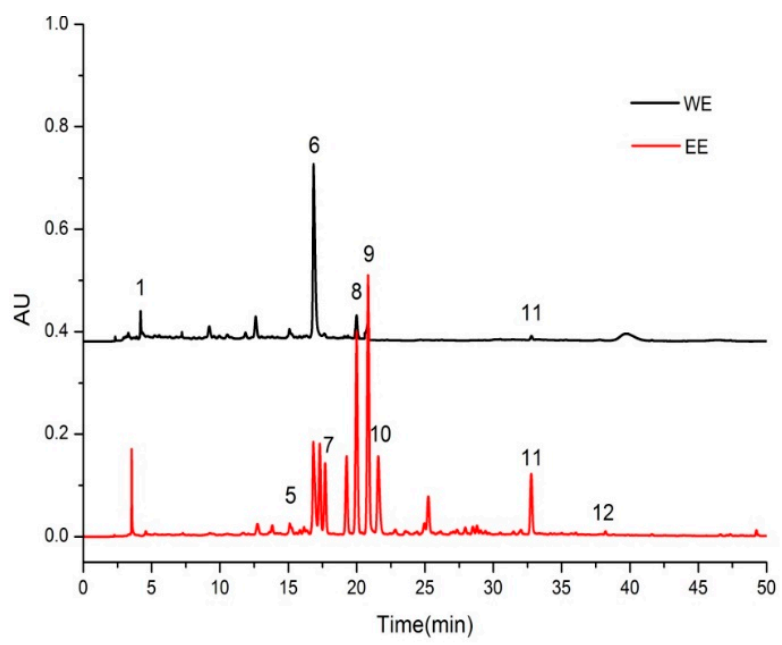

(b)

Figure 1. HPLC spectra of polyphenol standards (a) and polyphenols in guava leaf water extract/ethanolic extract (b); 1. Gallic acid, 2. Chlorogenic acid, 3. P-hydroxybenzoic acid, 4. Caffeic acid, 5. Rutin, 6. Ellagic acid, 7. Isoquercitrin, 8. quercetin-3-O- $\beta$-D-xylopyranoside, 9. Avicularin, 10. Quercitrin, 11. Quercetin, 12. Kaempferol.

\subsection{FTIR Spectra of Films}

The location and intensity of the characteristic absorption peaks of SAF, WEF and EEF are shown in Figure 2. The FTIR spectra of SAF and WEF showed very similar characteristic peaks. For SAF, a broad absorption band at $3250 \mathrm{~cm}^{-1}$ was attributed to the $\mathrm{O}-\mathrm{H}$ stretching vibration which was affected by the inter-molecular or intra-molecular hydrogen bonds [27]. The peaks at $2940 \mathrm{~cm}^{-1}, 1600 \mathrm{~cm}^{-1}$ and $1400 \mathrm{~cm}^{-1}$ were assigned to $\mathrm{C}-\mathrm{H}$ stretching [27], $\mathrm{C}=\mathrm{O}$ vibration [28] and $\mathrm{C}-\mathrm{H}$ stretching [29] respectively. The absorption ranged from 1260 to $1000 \mathrm{~cm}^{-1}$ and was due to the stretching vibrations of the $\mathrm{C}-\mathrm{O}-\mathrm{C}$ and $\mathrm{C}-\mathrm{OH}$ groups. The sodium alginate film had a strong absorption peak at $1030 \mathrm{~cm}^{-1}$ due to the presence of the glycosidic bond (C-O-C) [28]. WEF exhibited characteristic bands at $3280 \mathrm{~cm}^{-1}$, $2940 \mathrm{~cm}^{-1}, 1600 \mathrm{~cm}^{-1}, 1400 \mathrm{~cm}^{-1}$ and $1020 \mathrm{~cm}^{-1}$. An obvious decrease and a slight shift of the band can be observed from $3280 \mathrm{~cm}^{-1}$ to $3250 \mathrm{~cm}^{-1}$. This phenomenon also occurred in EEF, the absorption band of O-H significantly decreased and shifted from $3260 \mathrm{~cm}^{-1}$ to $3250 \mathrm{~cm}^{-1}$. In addition, those absorption peaks located at $2920 \mathrm{~cm}^{-1}, 1590 \mathrm{~cm}^{-1}$ and $1020 \mathrm{~cm}^{-1}$ had a slight shift in EEF from that of SAF, which was indicative of the interactions between the sodium alginate and extracts from guava leaves. Previous studies indicated that the changes of the peak position and intensity were induced by hydrogen bonds between polyphenols and sodium alginate [30,31]. Stronger intermolecular interactions could improve the physical properties of the films, such as the water barrier property and tensile strength.

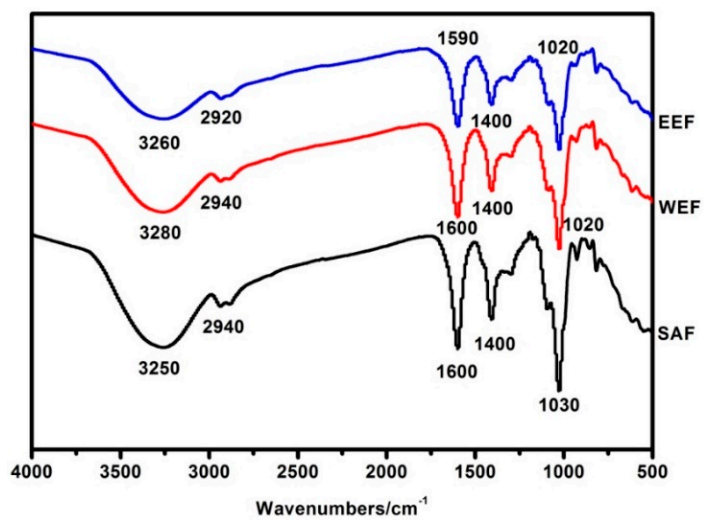

Figure 2. FT-IR spectra of SAF (Sodium alginate film), WEF (Sodium alginate incorporating water extract film) and EEF (Sodium alginate incorporating ethanolic extract film). 


\subsection{Microstructure of Films}

The microstructures of the films were magnified 50 times and 8000 times by SEM, respectively, as shown in Figure 3. From the magnified images of 50 times, it can be seen that the surface of all the grinded film samples were relatively smooth and the cross section was compact. From the magnified images of 8000 times, there were bulges and several cracks in the plain sodium alginate film, which could exert some adverse effects on the film properties such as, moisture resistance and the mechanical property. This result confirmed the fact that SAF possessed poor moisture resistance and tensile strength. After incorporation of the guava leaf extract, the composite films, especially EEF, appeared more compact and continuous owing to the formation of the hydrogen bond between the guava leaf extract and sodium alginate. Dou et al. observed a continuous surface without holes or friable areas, and the denser structure of gelatin-sodium alginate films with tea polyphenol [32]. The low WVP value and the better mechanical property were attributed to the more compact structure.

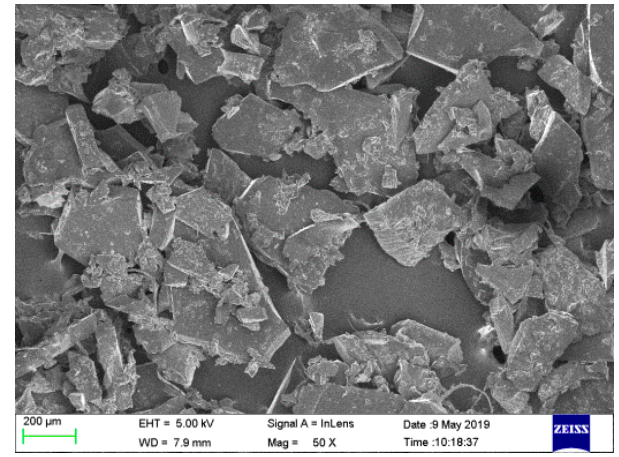

(a)

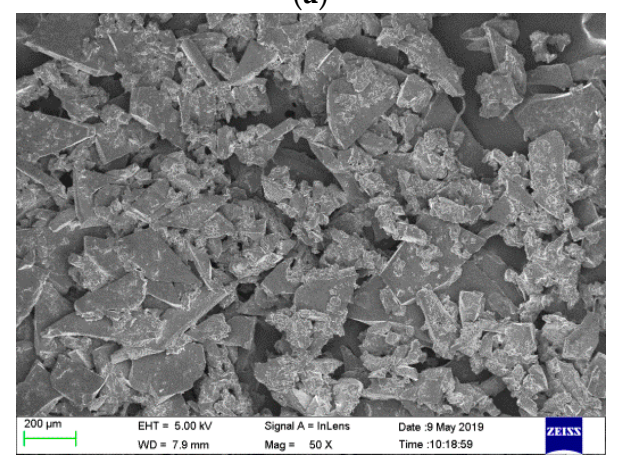

(c)

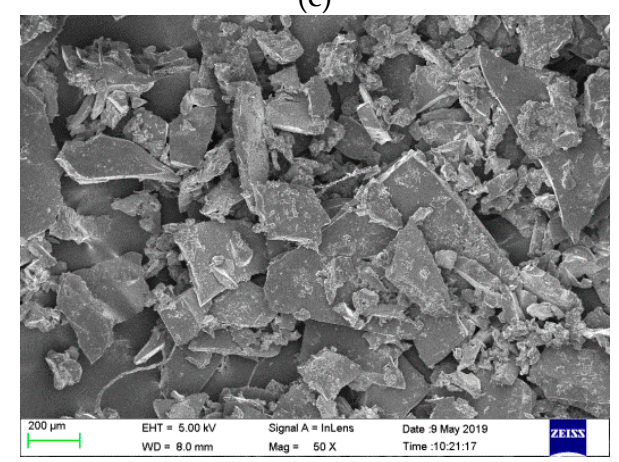

(e)

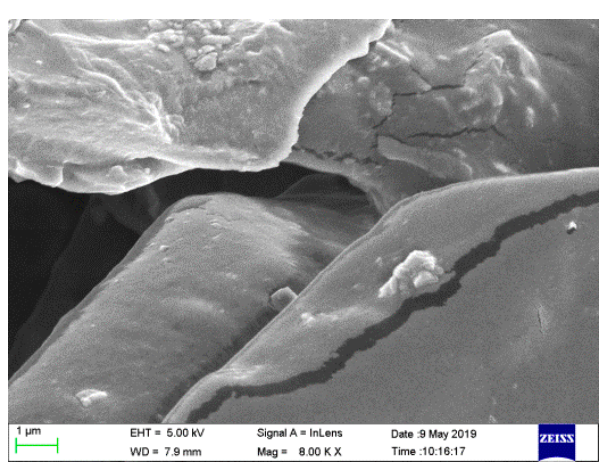

(b)

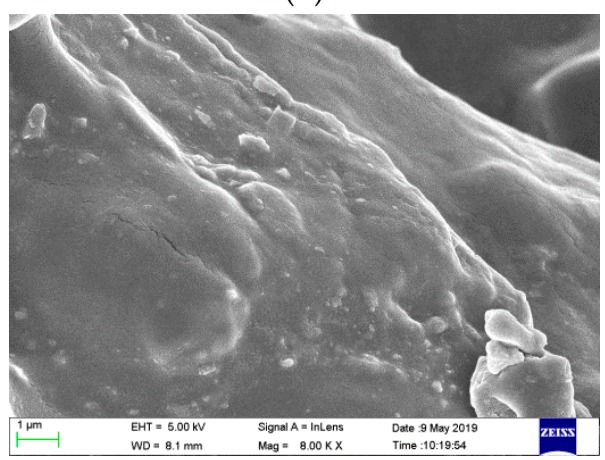

(d)

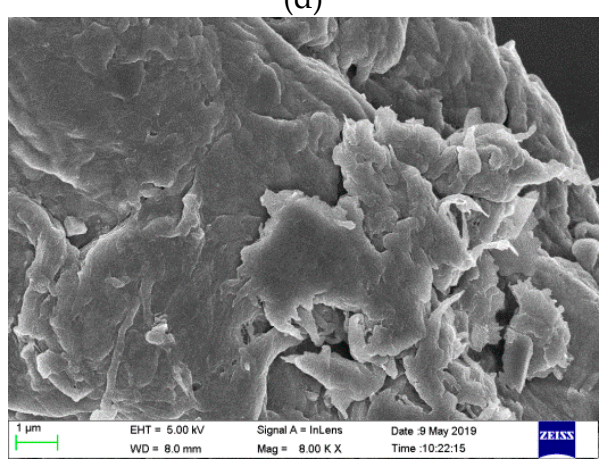

(f)

Figure 3. Cont. 


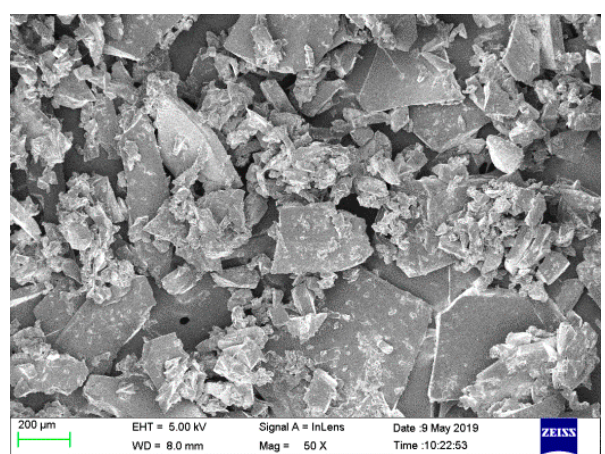

(g)

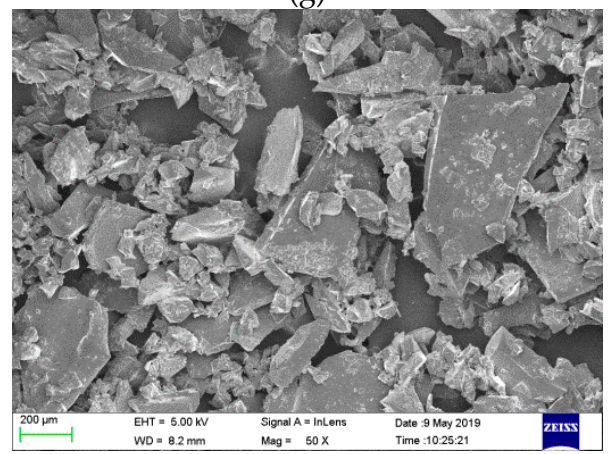

(i)

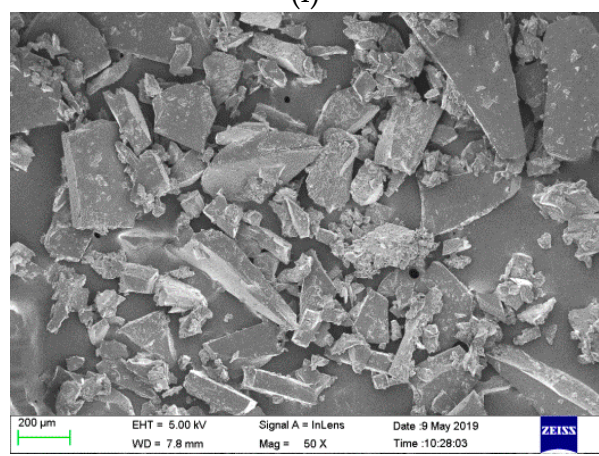

$(\mathrm{k})$

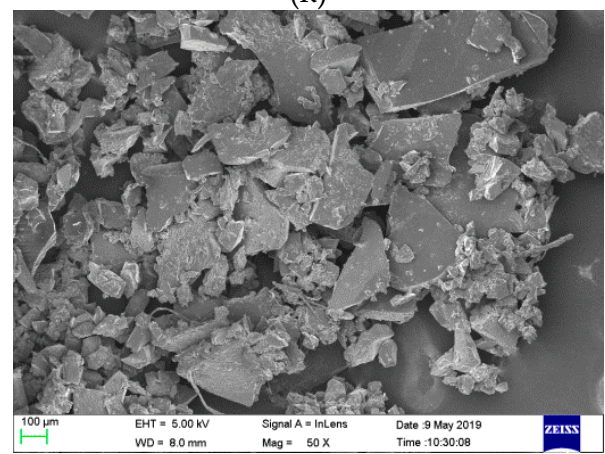

(m)

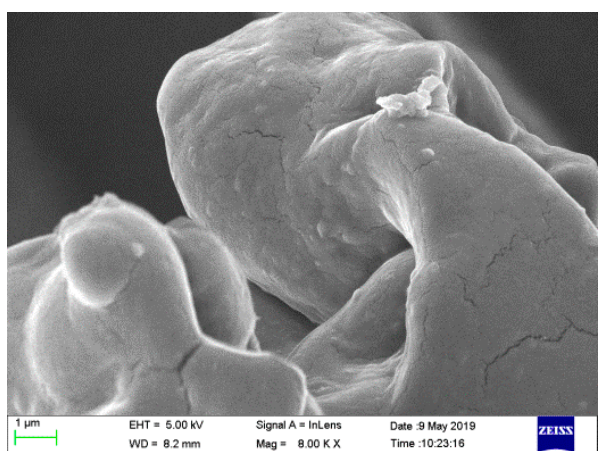

(h)

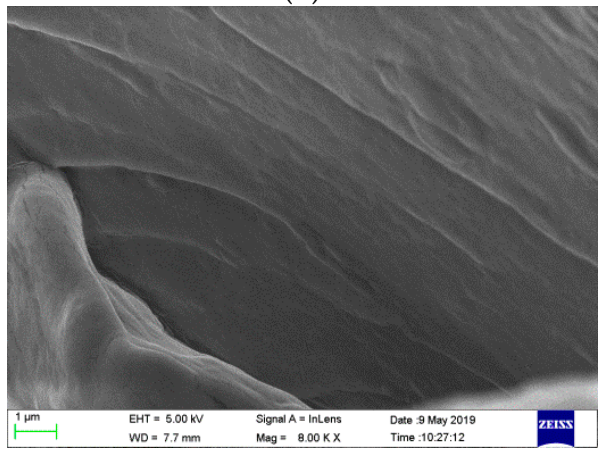

(j)

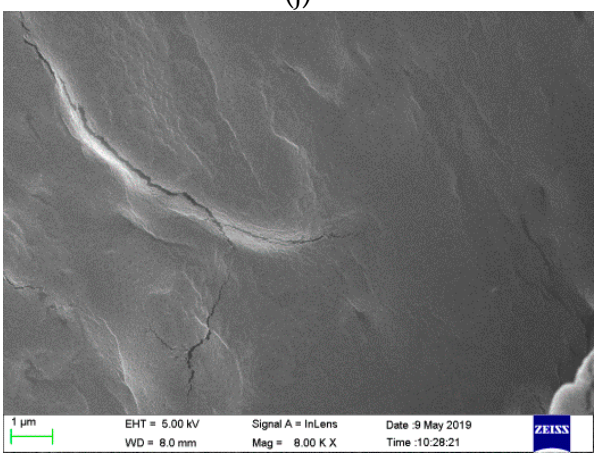

(1)

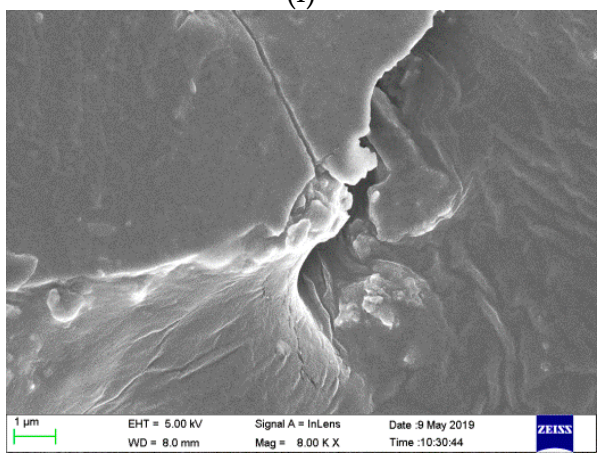

(n)

Figure 3. SEM micrographs of films: a, c, e, g, i, k, m (SAF, 10\% WEF, 15\% WEF, 20\% WEF, 10\% EEF, $15 \%$ EEF and 20\% EEF, magnification: $50 \times)$ and $\mathbf{b}, \mathbf{d}, \mathbf{f}, \mathbf{h}, \mathbf{j}, \mathbf{1}, \mathbf{n}(\mathrm{SAF}, 10 \% \mathrm{WEF}, 15 \% \mathrm{WEF}, 20 \% \mathrm{WEF}$, $10 \% \mathrm{EEF}, 15 \% \mathrm{EEF}$ and $20 \% \mathrm{EEF}$, magnification: $8000 \times)$.

\subsection{Film Appearance}

Color is a significant attribute of the product, which affects the product appearance and uses. As illustrated in Figure 4, sodium alginate-WE films became yellow with the addition of WE and the color deepened with the higher content of WE. The sodium alginate-EE films became brown with the 
incorporation of EE and the color also deepened with the increasing EE content. The color parameters of the different films are listed in Table 2. The films incorporating WE and EE had lower L values than the plain sodium alginate film, which were relatively dark $(p<0.05)$. The higher concentration of the guava leaf extract was, the lower L value obtained. Nevertheless, the $b$ values evidently increased $(p<0.05)$. This indicated the color of the film tended to yellowness. Except for $20 \% \mathrm{EEF}$, the A values of the other films were positive, indicating the tendency toward redness. The total color differences $(\Delta \mathrm{E})$ of all the composite films were markedly higher than the plain sodium alginate film $(p<0.05)$. Dou et al. found that tea polyphenols reduced the L values and increased the A and B values of the composite films as compared with the gelatin-sodium alginate film [32]. Considering the opacity of the composite films, they can be applicable for foods susceptible to light exposure.

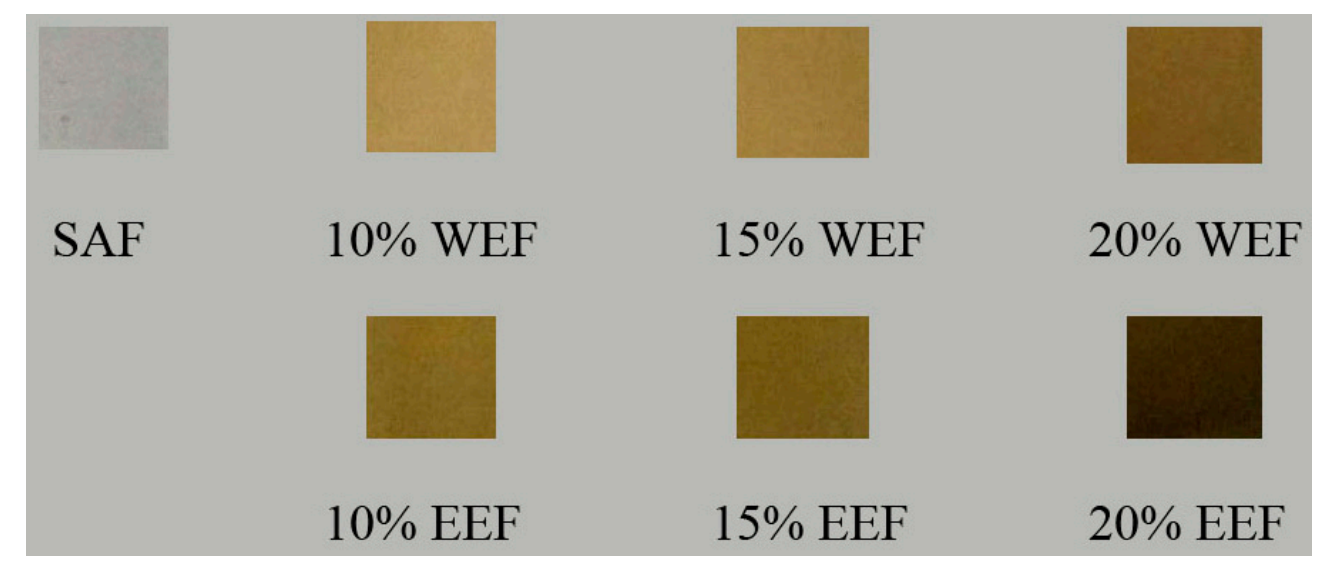

Figure 4. Physical appearances of the different films.

Table 2. Color parameters of the different films.

\begin{tabular}{ccccc}
\hline Films & L & A & B & $\Delta$ E \\
\hline SAF & $85.84 \pm 0.38 \mathrm{a}$ & $0.55 \pm 0.46 \mathrm{c}$ & $-2.57 \pm 0.14 \mathrm{e}$ & $0.49 \pm 0.43 \mathrm{e}$ \\
$10 \%$ WEF & $75.06 \pm 2.48 \mathrm{~b}$ & $2.29 \pm 0.92 \mathrm{~b}$ & $24.41 \pm 3.99 \mathrm{~d}$ & $29.50 \pm 4.67 \mathrm{~d}$ \\
$15 \% \mathrm{WEF}$ & $72.81 \pm 1.34 \mathrm{~b}$ & $2.87 \pm 0.33 \mathrm{~b}$ & $29.26 \pm 1.12 \mathrm{c}$ & $34.86 \pm 1.48 \mathrm{c}$ \\
$20 \% \mathrm{WEF}$ & $69.99 \pm 1.05 \mathrm{c}$ & $4.74 \pm 0.56 \mathrm{a}$ & $34.74 \pm 1.53 \mathrm{~b}$ & $41.14 \pm 1.87 \mathrm{~b}$ \\
$10 \% \mathrm{EEF}$ & $68.12 \pm 2.10 \mathrm{~cd}$ & $0.12 \pm 0.74 \mathrm{~cd}$ & $34.20 \pm 1.77 \mathrm{~b}$ & $41.24 \pm 2.49 \mathrm{~b}$ \\
$15 \% \mathrm{EEF}$ & $66.10 \pm 0.82 \mathrm{~d}$ & $2.37 \pm 0.08 \mathrm{~b}$ & $37.01 \pm 0.80 \mathrm{ab}$ & $44.25 \pm 1.06 \mathrm{~b}$ \\
$20 \% \mathrm{EEF}$ & $62.06 \pm 0.32 \mathrm{e}$ & $-0.39 \pm 0.38 \mathrm{~d}$ & $39.62 \pm 0.22 \mathrm{a}$ & $48.88 \pm 0.06 \mathrm{a}$ \\
\hline
\end{tabular}

Values are given as the mean $\pm \mathrm{SD}(\mathrm{n}=3)$. Letters $(\mathrm{a}-\mathrm{e})$ indicated significant differences $(p<0.05)$.

\subsection{Moisture Content, Water Solubility, Thickness and Water Vapor Permeability}

The moisture content, water solubility, thickness and water vapor permeability of the films are presented in Table 3.

The moisture content of the composite films remarkably reduced compared with the control sodium alginate film, ranging from $66.92 \%$ to $17.24 \%(p<0.05)$. The plain sodium alginate film presented a much higher moisture content due to the abundant hydrophilic groups $(-\mathrm{OH}$ and $-\mathrm{COOH})$ in the sodium alginate molecules. When WE or EE was added into sodium alginate, the hydroxyl groups in the extracts could form intermolecular hydrogen bonds with the hydrophilic groups in sodium alginate. Therefore, the interaction between the water and composite matrix was reduced. A similar variation tendency of the moisture content was also reported by Wu et al. when pomelo peel flours films incorporated tea polyphenol [12].

Water solubility is a reflex of the water resistance of the films and coatings. The plain sodium alginate film exhibited the lowest water solubility $(p<0.05)$. The water solubility of the films became better with the increase of the WE/EE content. The improved water solubility was attributed to the 
hydrophilic groups of polyphenols in WE and EE that can easily bind with water. A similar trend occurred in the chitosan films with the addition of apple polyphenols [31].

The composite films were much thinner than the plain sodium alginate film $(p<0.05)$. With the increasing of WE concentration, the thickness of the sodium alginate-WE films decreased. In contrast, the thickness of the sodium alginate-EE films increased with the increasing of the EE concentration because of the more amount of solid contents.

WVP reflects the ability of the film to prevent moisture transfer [33]. WVP is influenced by many factors such as thickness, components, humidity, water activity and so on [34]. The composite films exhibited much lower WVP values than the plain sodium alginate film $(p<0.05)$. Further, $10 \%$ EEF reached the minimum WVP value of $0.55 \times 10^{-11} \mathrm{~g} \cdot \mathrm{Pa}^{-1} \cdot \mathrm{s}^{-1} \cdot \mathrm{cm}^{-1}$, which significantly decreased by $69.27 \%$ compared with SAF. The results revealed the incorporation of the guava leaf extract could greatly improve the water-resistant property of the sodium alginate film. Previous studies reported that the dense networks formed through intermolecular interactions between polyphenols and biopolymers contributed to the lower WVP values of the composite films [12,33]. The WVP values of sodium alginate-WE films significantly decreased when the WE content increased from 10 to $20 \%(p<0.05)$. The sodium alginate-EE films gradually increased the WVP values with more addition of EE $(p<0.05)$. It is likely that the strong interfacial interaction between phenolics and sodium alginate could improve moisture resistance. However, the high content of phenolics might accumulate in the polymer matrix to produce voids, leading to higher WVP values [12].

Table 3. Moisture content, water solubility, thickness and water vapor permeability of the films.

\begin{tabular}{|c|c|c|c|c|}
\hline Films & $\mathrm{MC} / \%$ & Solubility/\% & Thickness/mm & $\begin{array}{c}\mathrm{WVP} / \times 10^{-11} \\
\mathrm{~g} \cdot \mathrm{Pa}^{-1} \cdot \mathrm{s}^{-1} \mathrm{~cm}^{-1}\end{array}$ \\
\hline SAF & $66.92 \pm 1.58 a$ & $76.31 \pm 0.51 f$ & $0.161 \pm 0.030 \mathrm{a}$ & $1.79 \pm 0.02 \mathrm{a}$ \\
\hline $10 \%$ WEF & $28.97 \pm 0.37 d$ & $83.49 \pm 0.48 \mathrm{e}$ & $0.087 \pm 0.015 b$ & $0.95 \pm 0.01 b$ \\
\hline $15 \% \mathrm{WEF}$ & $36.26 \pm 1.03 c$ & $89.39 \pm 0.78 d$ & $0.075 \pm 0.008 b c$ & $0.83 \pm 0.01 c$ \\
\hline $20 \% \mathrm{WEF}$ & $38.49 \pm 0.50 b$ & $98.46 \pm 0.83 a$ & $0.057 \pm 0.006 \mathrm{~cd}$ & $0.63 \pm 0.01 \mathrm{e}$ \\
\hline $10 \% \mathrm{EEF}$ & $20.71 \pm 0.73 e$ & $92.74 \pm 0.77 c$ & $0.050 \pm 0.010 \mathrm{~d}$ & $0.55 \pm 0.03 f$ \\
\hline $15 \%$ EEF & $18.18 \pm 0.44 \mathrm{f}$ & $93.89 \pm 0.20 b$ & $0.055 \pm 0.007 \mathrm{~cd}$ & $0.61 \pm 0.02 \mathrm{e}$ \\
\hline $20 \%$ EEF & $17.24 \pm 0.33 f$ & $94.03 \pm 0.28 b$ & $0.068 \pm 0.015 c$ & $0.75 \pm 0.02 d$ \\
\hline
\end{tabular}

Data are presented as the mean $\pm \mathrm{SD}(\mathrm{n}=6$ for thickness, $\mathrm{n}=3$ for MC, solubility and WVP). Letters (a-f) indicated significant differences $(p<0.05)$.

\subsection{Mechanical Properties of Films}

The mechanical strength and flexibility of the film are usually reflected by the tensile strength and elongation at the break [35]. The mechanical properties of the plain sodium alginate films and the composite films are summarized in Table 4 . The addition of the guava leaf extract caused a significant increase in the tensile strength and a significant decrease in the elongation at the break $(p<0.05)$ compared to the plain sodium alginate film. Overall, $10 \%$ WEF had preferable mechanical properties, tensile strength and elongation which were $10.86 \mathrm{MPa}$ and $22.47 \%$, respectively. The value of the tensile strength and elongation declined with increasing the WE proportion, while the mechanical properties of EEF were less affected by the extract. As the proportion of EE increased, the tensile strength of EEF increased first and then decreased, while elongation decreased. Dou et al.'s research also showed that the gelatin-sodium alginate film with higher tea polyphenols were stronger but more brittle [32].

Owing to the interfacial hydrogen interactions between sodium alginate and the guava leaf extract, a more compact structure of the composite film was obtained. Thus, the tensile strength of the composite film was enhanced. However, the tensile strength of the films decreased at a higher proportion of the extracts. The excessive proportion of the extracts may result in uneven dispersion in the mixture. 
Table 4. Mechanical properties of the films.

\begin{tabular}{ccc}
\hline Films & Tensile Strength/MPa & Elongation/\% \\
\hline SAF & $1.11 \pm 0.16 \mathrm{~d}$ & $88.16 \pm 1.29 \mathrm{a}$ \\
$10 \% \mathrm{WEF}$ & $10.86 \pm 0.36 \mathrm{~b}$ & $22.47 \pm 2.39 \mathrm{~b}$ \\
$15 \% \mathrm{WEF}$ & $9.39 \pm 0.06 \mathrm{~b}$ & $17.82 \pm 1.24 \mathrm{c}$ \\
$20 \% \mathrm{WEF}$ & $5.90 \pm 0.29 \mathrm{c}$ & $6.78 \pm 0.83 \mathrm{~d}$ \\
$10 \% \mathrm{EEF}$ & $17.15 \pm 1.19 \mathrm{a}$ & $6.38 \pm 1.05 \mathrm{~d}$ \\
$15 \% \mathrm{EEF}$ & $17.36 \pm 1.72 \mathrm{a}$ & $5.44 \pm 1.97 \mathrm{~d}$ \\
$20 \% \mathrm{EEF}$ & $8.52 \pm 1.53 \mathrm{~b}$ & $5.36 \pm 1.62 \mathrm{~d}$
\end{tabular}

Values are given as the mean $\pm \mathrm{SD}(\mathrm{n}=3)$. Different letters $(\mathrm{a}-\mathrm{d})$ indicated significant differences $(p<0.05)$.

\subsection{Antioxidant Properties of Films}

The composite films displayed strong DPPH free radical scavenging ability. Except for the SA film, the composite films presented dose-independent DPPH radical scavenging activities in Figure 5A. The DPPH radical scavenging rate of the different composite films significantly increased with the increasing amount of the films from $10 \mathrm{mg}$ to $30 \mathrm{mg}(p<0.05)$. Meanwhile, when the proportion of the guava leaf extract increased from $10 \%$ to $20 \%$, the DPPH radical scavenging abilities of the films were also improved to a certain extent. Conversely, the plain sodium alginate film showed a weak DPPH radical scavenging ability. As shown in Figure 5B, all composite films exhibited time-dependent DPPH radical scavenging capabilities. The clearance rate markedly increased within $30 \mathrm{~min}$, then slowed down, and reached the maximum at $50 \mathrm{~min}$. The order of the DPPH free radical scavenging ability of these films was as follow: EEF $>$ WEF $>$ SAF. The differences of antioxidant activity among the films were ascribed to the kinds and contents of polyphenols. Polyphenols in ethanolic extract are more abundant than those in the water extract. Similar enhancements in scavenging radical assays were also attained when apple polyphenol, maqui berry extract and black soybean seed coat extract were added into the chitosan film $[31,36,37]$. Therefore, the guava leaf extract can greatly improve the anti-oxidative capacity of the packaging materials to prevent food from oxidative deterioration.

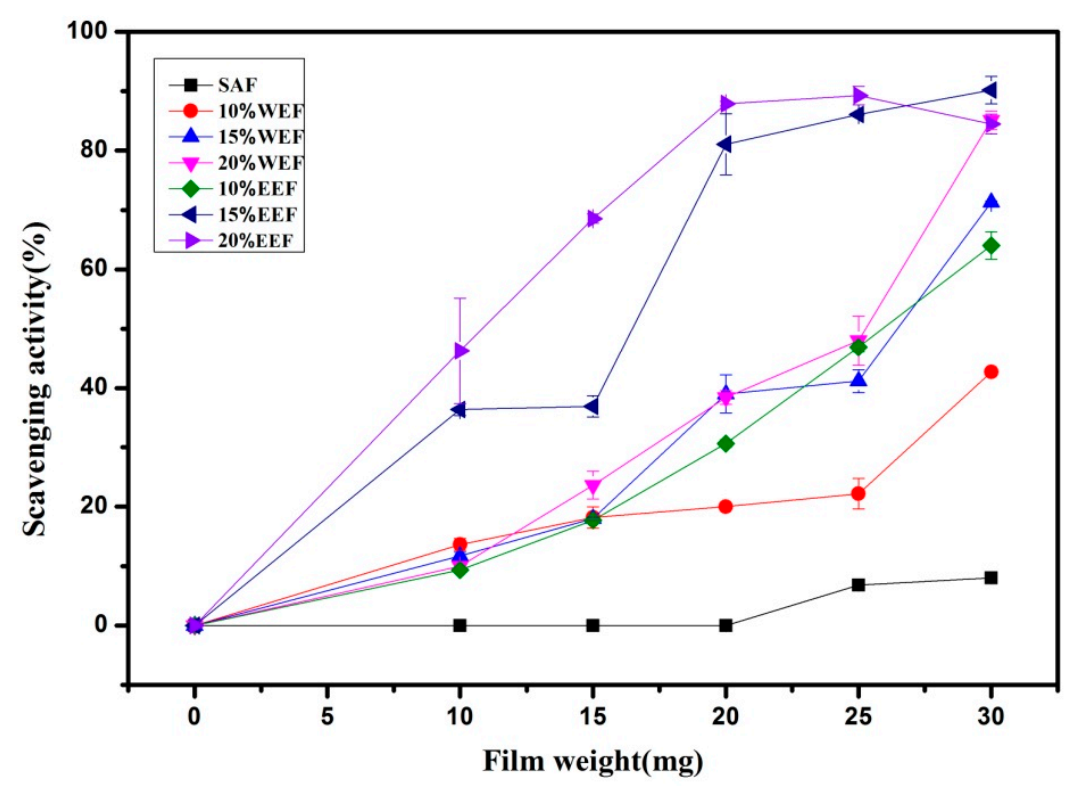

(A)

Figure 5. Cont. 


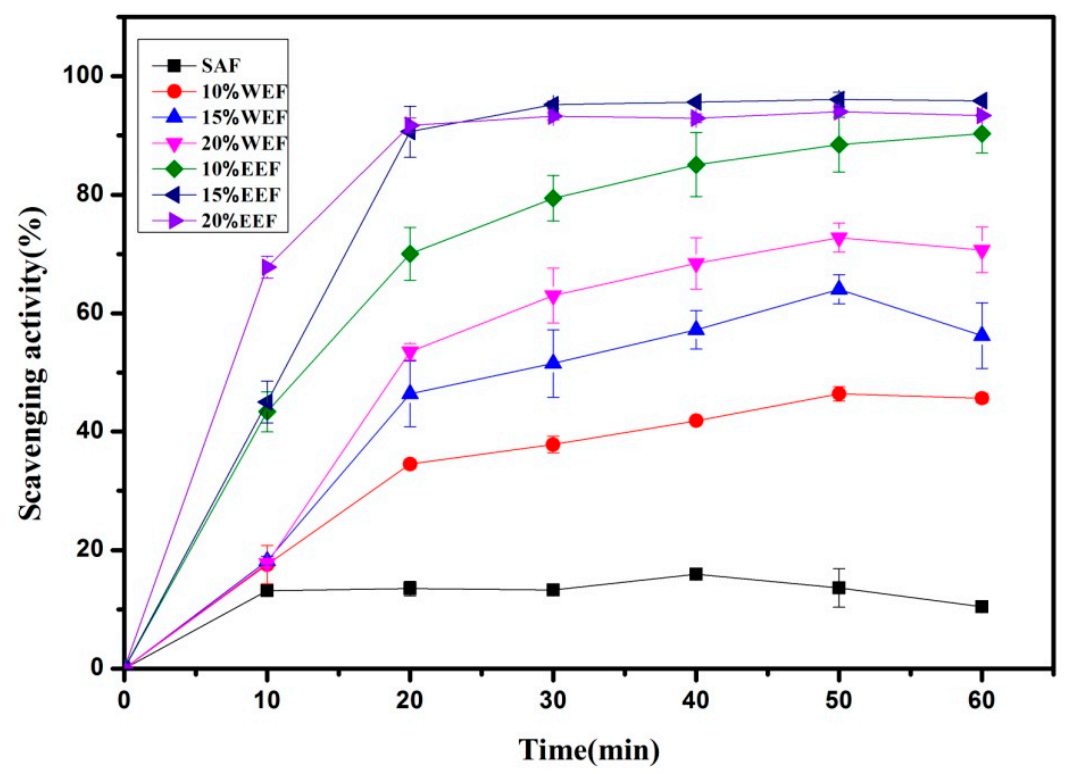

(B)

Figure 5. Weight-dependent (A) and time-dependent (B) DPPH radical scavenging ability of the films.

\subsection{Antibacterial Properties of Films}

The antibacterial capacity of the different films against E. coli and S. aureus is presented in Figure 6 and Table 5. The plain sodium alginate films exhibited a certain antimicrobial ability against $E$. coli and $S$. aureus. With increasing the proportion of the guava leaf extract, the diameter of the inhibition zones gradually increased, especially EEF $(p<0.05)$. Further, $10 \%$ EE could greatly improve the inhibitory effect of the SA film on E. coli and S. aureus. 15\% WE markedly improved the inhibitory effect of the SA film on E. coli $(p<0.05)$. Furthermore, $10 \%$ WE significantly enhanced the inhibitory effect of the SA film on $S$. aureus $(p<0.05)$. The SA/EE films showed better antibacterial properties than the $\mathrm{SA} / \mathrm{WE}$ films. On the one hand, the polyphenol content of the ethanolic extract from guava leaves was 1.6 times higher than the water extract. On the other hand, the different kinds of polyphenol exert different influences on bacteria, and the polyphenol mixture is generally much more active than either polyphenol alone. It was reported that the combinations of rutin and quercetin, quercetin and quercitrin, kaempherol and rutin showed better antibacterial activity than either flavonoid alone [38]. $\mathrm{Wu}$ et al. observed that the addition of tea polyphenols significantly promoted the antimicrobial property of the composite film compared with the control [12].

Table 5. Antimicrobial properties of the films.

\begin{tabular}{ccc}
\hline \multirow{2}{*}{ Films } & \multicolumn{2}{c}{ Inhibition Zone Diameter $(\mathbf{m m})$} \\
\cline { 2 - 3 } & E. coli $(-)$ & S. aureus $(+)$ \\
\hline SAF & $13.83 \pm 0.16 \mathrm{~d}$ & $14.00 \pm 0.46 \mathrm{~d}$ \\
$10 \% \mathrm{WEF}$ & $14.08 \pm 0.25 \mathrm{~d}$ & $15.85 \pm 0.38 \mathrm{c}$ \\
$15 \% \mathrm{WEF}$ & $14.52 \pm 0.23 \mathrm{c}$ & $16.30 \pm 0.42 \mathrm{c}$ \\
$20 \% \mathrm{WEF}$ & $15.17 \pm 0.26 \mathrm{c}$ & $16.33 \pm 0.39 \mathrm{c}$ \\
$10 \% \mathrm{EEF}$ & $15.47 \pm 0.45 \mathrm{c}$ & $16.03 \pm 0.37 \mathrm{c}$ \\
$15 \% \mathrm{EEF}$ & $21.17 \pm 0.35 \mathrm{~b}$ & $17.22 \pm 0.40 \mathrm{~b}$ \\
$20 \% \mathrm{EEF}$ & $23.20 \pm 0.36 \mathrm{a}$ & $18.22 \pm 0.30 \mathrm{a}$
\end{tabular}

Values are given as the mean $\pm \mathrm{SD}(\mathrm{n}=3)$. Different letters (a-f) indicated significant differences $(p<0.05)$. 

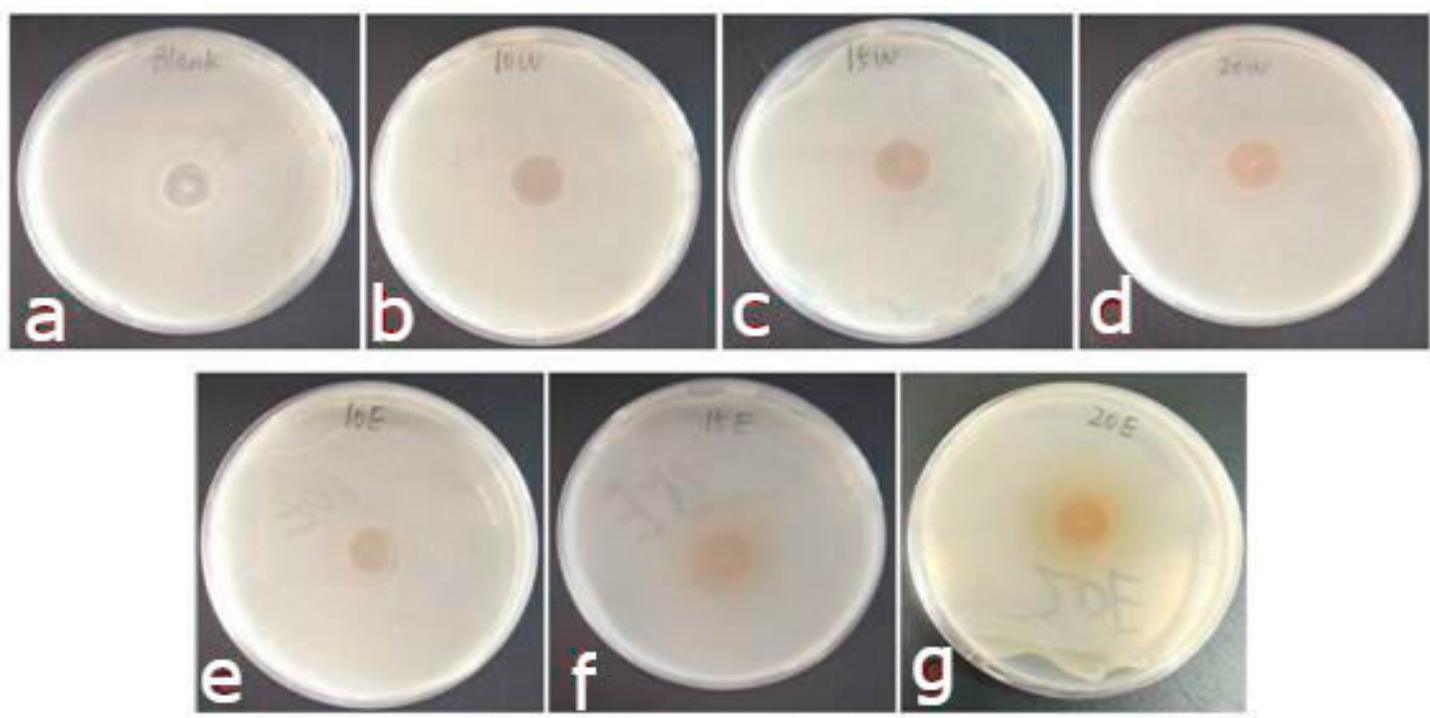

(A)The inhibitory effect of the films on E. coli
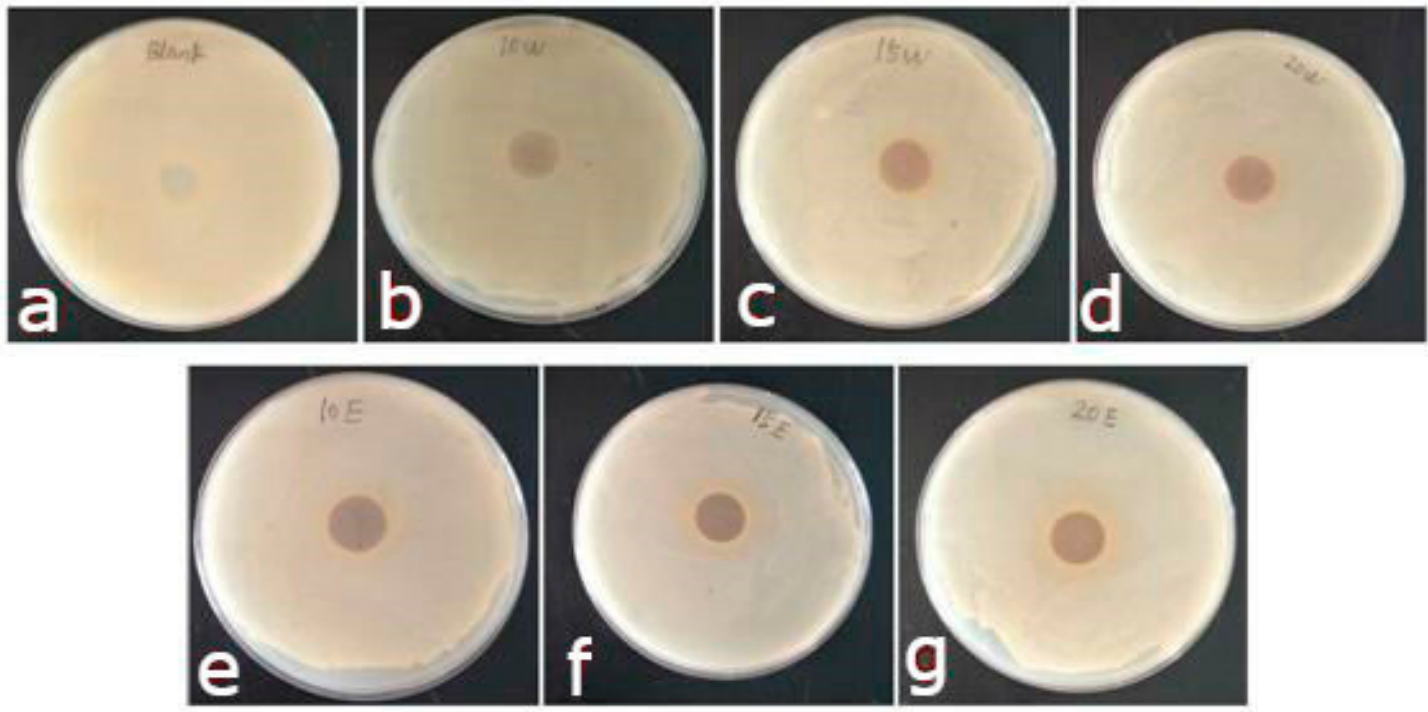

(B)The inhibitory effect of the films on S. aureus

Figure 6. The antibacterial activity of the different films against E. coli (A) and S. aureus (B). (a: SAF,

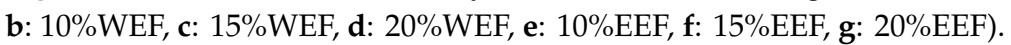

\section{Conclusions}

Bioactive films were successfully developed by adding the water extract/ethanolic extract from the guava leaves into sodium alginate. The guava leaf extracts significantly enhanced the antioxidant and antibacterial abilities as well as the tensile strength and water-resistant properties of the composite films when compared to the plain sodium alginate film. The water resistance, tensile strength, antioxidant activity and antibacterial activity decreased in the order of EEF $>$ WEF $>$ SAF. The results provide a strategy to utilize agricultural by-products which provide functional ingredients. The results can further provide an insight to active packaging for food.

Author Contributions: Y.L. designed the experiments and wrote the manuscript; H.L., S.Y. and J.Z. were responsible for the experiments implementation and data analysis. Z.W. revised the manuscript.

Funding: This research is funded by Science and Technology Project of Guangdong Province, China (2017B020207003) and Guangdong special funds for science and technology innovation strategy, China (JK2018-352-0203). 
Conflicts of Interest: The authors declare that there are no conflicts of interest.

\section{References}

1. Wright, S.L.; Kelly, F.J. Threat to human health from environmental plastics. BMJ 2017, 358, j4334. [CrossRef] [PubMed]

2. Santeramo, F.G.; Carlucci, D.; De Devitiis, B.; Seccia, A.; Stasi, A.; Viscecchia, R.; Nardone, G. Emerging trends in European food, diets and food industry. Food Res. Int. 2018, 104, 39-47. [CrossRef] [PubMed]

3. Mikkonen, K.S.; Tenkanen, M. Sustainable food-packaging materials based on future biorefinery products: Xylans and mannans. Trends Food Sci. Technol. 2012, 28, 90-102. [CrossRef]

4. Singh, P.; Magalhães, S.; Alves, L.; Antunes, F.; Miguel, M.; Lindman, B.; Medronho, B. Cellulose-based edible films for probiotic entrapment. Food Hydrocoll. 2019, 88, 68-74. [CrossRef]

5. Ananey-Obiri, D.; Matthews, L.; Azahrani, M.H.; Ibrahim, S.A.; Galanakis, C.M.; Tahergorabi, R. Application of protein-based edible coatings for fat uptake reduction in deep-fat fried foods with an emphasis on muscle food proteins. Trends Food Sci. Technol. 2018, 80, 167-174. [CrossRef]

6. Abdel Aziz, M.S.; Salama, H.E.; Sabaa, M.W. Biobased alginate/castor oil edible films for active food packaging. LWT 2018, 96, 455-460. [CrossRef]

7. Yang, M.; Wang, L.; Xia, Y. Ammonium persulphate induced synthesis of polymethyl methacrylate grafted sodium alginate composite films with high strength for food packaging. Int. J. Biol. Macromol. 2019, 124, 1238-1245. [CrossRef] [PubMed]

8. Wang, X.; Zhang, Y.; Liang, H.; Zhou, X.; Fang, C.; Zhang, C.; Luo, Y. Synthesis and properties of castor oil-based waterborne polyurethane/sodium alginate composites with tunable properties. Carbohydr. Polym. 2019, 208, 391-397. [CrossRef] [PubMed]

9. Matta, E.; Tavera-Quiroz, M.J.; Bertola, N. Active edible films of methylcellulose with extracts of green apple (Granny Smith) skin. Int. J. Biol. Macromol. 2019, 124, 1292-1298. [CrossRef] [PubMed]

10. Pisoschi, A.M.; Pop, A. The role of antioxidants in the chemistry of oxidative stress: A review. Eur. J. Med. Chem. 2015, 97, 55-74. [CrossRef]

11. Taguri, T.; Tanaka, T.; Kouno, I. Antibacterial Spectrum of Plant Polyphenols and Extracts Depending upon Hydroxyphenyl Structure. Biol. Pharm. Bull. 2006, 29, 2226-2235. [CrossRef] [PubMed]

12. Wu, H.; Lei, Y.; Zhu, R.; Zhao, M.; Lu, J.; Xiao, D.; Jiao, C.; Zhang, Z.; Shen, G.; Li, S. Preparation and characterization of bioactive edible packaging films based on pomelo peel flours incorporating tea polyphenol. Food Hydrocoll. 2019, 90, 41-49. [CrossRef]

13. Talón, E.; Trifkovic, K.T.; Nedovic, V.A.; Bugarski, B.M.; Vargas, M.; Chiralt, A.; González-Martínez, C. Antioxidant edible films based on chitosan and starch containing polyphenols from thyme extracts. Carbohydr. Polym. 2017, 157, 1153-1161. [CrossRef] [PubMed]

14. Gutiérrez, R.M.P.; Mitchell, S.; Solis, R.V. Psidium guajava: A review of its traditional uses, phytochemistry and pharmacology. J. Ethnopharmacol. 2008, 117, 1-27. [CrossRef] [PubMed]

15. Kaneko, K.; Suzuki, K.; Iwadate-Iwata, E.; Kato, I.; Uchida, K.; Onoue, M. Evaluation of Food-drug Interaction of Guava Leaf Tea: EVALUATION OF FOOD-DRUG INTERACTION OF GUAVA LEAF TEA. Phytother. Res. 2013, 27, 299-305. [CrossRef] [PubMed]

16. Nantitanon, W.; Yotsawimonwat, S.; Okonogi, S. Factors influencing antioxidant activities and total phenolic content of guava leaf extract. LWT-Food Sci. Technol. 2010, 43, 1095-1103. [CrossRef]

17. Wang, L.; Luo, Y.; Wu, Y.; Xia, F.; Wu, Z. Quickly verifying the antioxidant contribution of the individual composition in natural antioxidants by HPLC-free radical scavenging detection. LWT 2018, 96, 461-468. [CrossRef]

18. Biswas, B.; Rogers, K.; McLaughlin, F.; Daniels, D.; Yadav, A. Antimicrobial Activities of Leaf Extracts of Guava (Psidium guajava L.) on Two Gram-Negative and Gram-Positive Bacteria. Int. J. Microbiol. 2013, 2013, 746156. [CrossRef]

19. Yang, M.; Shi, J.; Xia, Y. Effect of SiO2, PVA and glycerol concentrations on chemical and mechanical properties of alginate-based films. Int. J. Biol. Macromol. 2018, 107, 2686-2694. [CrossRef]

20. Costa, M.J.; Marques, A.M.; Pastrana, L.M.; Teixeira, J.A.; Sillankorva, S.M.; Cerqueira, M.A. Physicochemical properties of alginate-based films: Effect of ionic crosslinking and mannuronic and guluronic acid ratio. Food Hydrocoll. 2018, 81, 442-448. [CrossRef] 
21. Salama, H.E.; Abdel Aziz, M.S.; Sabaa, M.W. Novel biodegradable and antibacterial edible films based on alginate and chitosan biguanidine hydrochloride. Int. J. Biol. Macromol. 2018, 116, 443-450. [CrossRef] [PubMed]

22. Ainsworth, E.A.; Gillespie, K.M. Estimation of total phenolic content and other oxidation substrates in plant tissues using Folin-Ciocalteu reagent. Nat. Protoc. 2007, 2, 875-877. [CrossRef] [PubMed]

23. Rivero, S.; García, M.A.; Pinotti, A. Correlations between structural, barrier, thermal and mechanical properties of plasticized gelatin films. Innov. Food Sci. Emerg. Technol. 2010, 11, 369-375. [CrossRef]

24. Petersen, D.; Link, R.; Kumaran, M. Interlaboratory Comparison of the ASTM Standard Test Methods for Water Vapor Transmission of Materials (E 96-95). J. Test. Eval. 1998, 26, 83-88. [CrossRef]

25. Shimada, K.; Fujikawa, K.; Yahara, K.; Nakamura, T. Antioxidative properties of xanthan on the autoxidation of soybean oil in cyclodextrin emulsion. J. Agric. Food Chem. 1992, 40, 945-948. [CrossRef]

26. Otoni, C.G.; de Moura, M.R.; Aouada, F.A.; Camilloto, G.P.; Cruz, R.S.; Lorevice, M.V.; de, F.F.; Soares, N.; Mattoso, L.H.C. Antimicrobial and physical-mechanical properties of pectin/papaya puree/cinnamaldehyde nanoemulsion edible composite films. Food Hydrocoll. 2014, 41, 188-194. [CrossRef]

27. Li, C.; Huang, Q.; Fu, X.; Yue, X.-J.; Liu, R.H.; You, L.-J. Characterization, antioxidant and immunomodulatory activities of polysaccharides from Prunella vulgaris Linn. Int. J. Biol. Macromol. 2015, 75, 298-305. [CrossRef] [PubMed]

28. Kacuráková, M. FT-IR study of plant cell wall model compounds: Pectic polysaccharides and hemicelluloses. Carbohydr. Polym. 2000, 43, 195-203. [CrossRef]

29. Coimbra, M.A.; Gonçalves, F.; Barros, A.S.; Delgadillo, I. Fourier Transform Infrared Spectroscopy and Chemometric Analysis of White Wine Polysaccharide Extracts. J. Agric. Food Chem. 2002, 50, 3405-3411. [CrossRef]

30. Liu, Y.; Cai, Y.; Jiang, X.; Wu, J.; Le, X. Molecular interactions, characterization and antimicrobial activity of curcumin-chitosan blend films. Food Hydrocoll. 2016, 52, 564-572. [CrossRef]

31. Sun, L.; Sun, J.; Chen, L.; Niu, P.; Yang, X.; Guo, Y. Preparation and characterization of chitosan film incorporated with thinned young apple polyphenols as an active packaging material. Carbohydr. Polym. 2017, 163, 81-91. [CrossRef] [PubMed]

32. Dou, L.; Li, B.; Zhang, K.; Chu, X.; Hou, H. Physical properties and antioxidant activity of gelatin-sodium alginate edible films with tea polyphenols. Int. J. Biol. Macromol. 2018, 118, 1377-1383. [CrossRef] [PubMed]

33. Yoshida, C.M.P.; Maciel, V.B.V.; Mendonça, M.E.D.; Franco, T.T. Chitosan biobased and intelligent films: Monitoring pH variations. LWT-Food Sci. Technol. 2014, 55, 83-89. [CrossRef]

34. Gutiérrez, T.J.; Tapia, M.S.; Pérez, E.; Famá, L. Structural and mechanical properties of edible films made from native and modified cush-cush yam and cassava starch. Food Hydrocoll. 2015, 45, 211-217. [CrossRef]

35. Pranoto, Y.; Salokhe, V.M.; Rakshit, S.K. Physical and antibacte rial properties of alginate-based edible film incorporated with garlic oil. Food Res. Int. 2005, 38, 267-272. [CrossRef]

36. Genskowsky, E.; Puente, L.A.; Pérez-Álvarez, J.A.; Fernandez-Lopez, J.; Muñoz, L.A.; Viuda-Martos, M. Assessment of antibacterial and antioxidant properties of chitosan edible films incorporated with maqui berry (Aristotelia chilensis). LWT-Food Sci. Technol. 2015, 64, 1057-1062. [CrossRef]

37. Wang, X.; Yong, H.; Gao, L.; Li, L.; Jin, M.; Liu, J. Preparation and characterization of antioxidant and pH-sensitive films based on chitosan and black soybean seed coat extract. Food Hydrocoll. 2019, 89, 56-66. [CrossRef]

38. Arima, H.; Ashida, H.; Danno, G. Rutin-enhanced Antibacterial Activities of Flavonoids against Bacillus cereus and Salmonella enteritidis. Biosci. Biotechnol. Biochem. 2002, 66, 1009-1014. [CrossRef]

(C) 2019 by the authors. Licensee MDPI, Basel, Switzerland. This article is an open access article distributed under the terms and conditions of the Creative Commons Attribution (CC BY) license (http://creativecommons.org/licenses/by/4.0/). 